\title{
Dietary quercetin abrogates hepatorenal oxidative damage associated with dichloromethane exposure in rats
}

\author{
Solomon E. Owumi ${ }^{\natural}$, Olabisi F. Danso ${ }^{2}$ and Magdalene E. Effiong ${ }^{2}$ \\ ${ }^{1}$ Cancer Research and Molecular Biology Laboratories, 2Industrial and Nutritional Biochemistry, Department of Biochemistry, College of Medi- \\ cine, University of Ibadan, Ibadan, Nigeria
}

Exposure to dichloromethane (DCM), a commonly used chlorinated solvent in industrial settings and for the production of many household products, reportedly elicits detrimental effects in animals and humans. The present study investigated the protective role of dietary quercetin on DCM-induced hepatorenal damage in rats. Experimental rats were orally administered with DCM $(150 \mathrm{mg} / \mathrm{kg})$ and $30 \mathrm{~min}$ later with quercetin at 10, 20 and $40 \mathrm{mg} / \mathrm{kg}$ or none for 7 consecutive days. The results indicated that DCM-mediated significant $(p<0.05)$ increases in serum alanine aminotransferase, aspartate aminotransferase, gamma glutamyl transferase and alkaline phosphatase activities as well as urea and creatinine levels were dose-dependently normalized to the control values in rats co-treated with quercetin. Further, quercetin co-treatment ameliorated DCM-mediated decrease in the hepatic and renal activities of superoxide dismutase, catalase, glutathione peroxidase and glutathione S-transferase as well as glutathione level in the treated rats. Moreover, quercetin co-treatment markedly reduced lipid peroxidation level and protected against histological changes in liver and kidney of the treated rats. Taken together, quercetin abrogated hepatorenal oxidative damage in DCM-treated rats via improvement of antioxidant status and suppression of oxidative damage.

Key words: dichloromethane, quercetin, hepatorenal, oxidative stress, rats

Received: 28 January, 2019; revised: 06 March, 2019; accepted: 15 March, 2019; available on-line: 08 April, 2019

『e-mail: zicri@hotmail.com

Acknowledgement of Financial Support: This work was completely supported by the personal contributions of the authors.

Abbreviations: ALT, alanine aminotransferase; AST, aspartate aminotransferase; ALP, alkaline phosphatase; CAT, catalase; CDNB, 1-chloro-2,4-dinitrobenzene; DCM, dichloromethane; DTNB, 5', 5'-dithiobis-2-nitrobenzoic acid; GGT, gamma glutamyl transferase; GPx, glutathione peroxidase; GSH, glutathione; GST, glutathione-Stransferase; $\mathrm{H}_{2} \mathrm{O}_{2}$, hydrogen peroxide; MDA, malondialdehyde; ROS, reactive oxygen species; SOD, superoxide dismutase; TBA, thiobarbituric acid; TCA, trichloroacetic acid; Qt, quercetin

\section{INTRODUCTION}

Dichloromethane (DCM; Fig. 1a) also known as methylene chloride is a colorless, volatile liquid with a sweet and pleasant fragrance. It is widely used as a solvent in pharmaceutical, textile and electronics manufacturing industries (Jianming et al., 2014). Moreover, DCM is a major constituent of many household products specifically lubricants, varnish removers and valve cleaners (ATSDR 2000, HPD 2009). However, owing to incorrect handling, storage and disposal practices, DCM is normally released into the environment including surface water, groundwater, drinking water supply wells globally including the United States (Shestakova \& Sillanpää, 2013, Hermon et al., 2018).

Acute and chronic exposure to DCM reportedly poses great threat to humans and ecosystems due to its toxicity, persistence, and bioaccumulation in the food chain (Tobajas et al., 2016). DCM, due to its lipophilicity is easily absorbed and metabolized in humans and animals resulting in multiple organ damage (Schlosser et al., 2015). Further, DCM has been shown to undergo both microsomal oxidation and cytosolic glutathione-conjugation pathways in the liver (Evans \& Caldwell, 2010; Schlosser et al., 2015). Epidemiological findings indicated that exposure to DCM is common in workplace leading to toxicity (Bonfiglioli et al., 2014). Previous experimental studies demonstrated that DCM is a lung and liver carcinogen in rodents (Condie et al., 1983; Their et al., 1998; Schlosser et al., 2015). However, the precise biochemical mechanisms involved in DCM-mediated hepatic and renal toxicity is not fully understood.

Quercetin, also known as 3,5,7,3',4'-pentahydroxyflavone (Fig. 1b), is a naturally occurring polyphenolic flavonoid commonly found in fruits and vegetables, such as onions, cabbages, berries, wines and apples (Boots et al., 2008, D'Andrea 2015). Quercetin daily dietary intake was estimated to be between 4 to $68 \mathrm{mg}$ /day (Chen et al., 2010). However, its quantity can rise to $200-500 \mathrm{mg} /$ day in people that eat large amount of flavonoid-rich fruits and vegetables (Costa et al., 2013). In fact, quercetin has an important nutraceutical and pharmaceutical applications (Nair et al., 2010; Pandey et al., 2018; Rauf et al., 2018). It is commercially available as a dietary supplement with a recommended dosage of $1 \mathrm{~g} /$ day (Harwood et al., 2007). Experimental findings demonstrated that quercetin elicits several health beneficial effects which is related to its ability to scavenge reactive oxygen radicals, inhibition of xanthine oxidase and oxidative stress in vitro and in vivo (Zizkova et al., 2017; Ebegboni et al., 2019; Houghton et al., 2018). Quercetin reportedly elicits several health beneficial effects on human health specifically, anti-inflammatory, anti-cancer, anti-viral and neuroprotective effects (Adedara et al., 2017; Sharma et<smiles>CCl</smiles><smiles></smiles>

Figure 1. Chemical structures of the tested compounds: (A) Dichloromethane (DCM) and (B) Quercetin. 
al., 2018; Babaei et al., 2018). Hitherto, there is no study in literature on the possible influence of quercetin on hepatic and renal toxicity induced by DCM. Thus, the present study investigated, for the first time, the role of quercetin on hepatorenal toxicity following exposure to DCM in male Wistar rats. To achieve this, we evaluated some hepatic and renal toxicity indices, antioxidant enzyme activities, lipid peroxidation along with histological alterations in the liver and kidney of experimental rats.

\section{MATERIALS AND METHODS}

Chemicals and reagents. Quercetin, dichloromethane (DCM), glutathione (GSH), thiobarbituric acid (TBA), epinephrine, 1-chloro-2,4-dinitrobenzene (CDNB), 5',5'-dithiobis-2-nitrobenzoic acid (DTNB) and hydrogen peroxide $\left(\mathrm{H}_{2} \mathrm{O}_{2}\right)$ were procured from SigmaAldrich Company, St. Louis, Missouri, United States. All other chemicals used in this study were of analytical grade and were purchased from the British Drug Houses (Poole, Dorset, UK). The kits used for the assessment of liver and kidney tests were purchased from Randox Laboratories Limited (UK).

Animal model and care. Forty male Wistar rats (7 weeks old, $147 \pm 4 \mathrm{~g}$ ) used for this study were purchased from the breeding colony of the Faculty of Veterinary Medicine, University of Ibadan, Nigeria. The rats were kept in plastic cages located in a well-ventilated vivarium with natural photoperiod of 12-hr light: 12-hr dark cycle. The rats had free access to rat chow and water and were adequately cared for according to the conditions specified in the 'Guide for the Care and Use of Laboratory Animals' by the National Institute of Health. All experimental protocols were performed after approval by the University of Ibadan Ethical Committee. The rats were acclimatized for a week before commencement of the experiment.

Experimental design. The rats were randomly allotted to six groups of eight rats each and were treated for 7 consecutive days. Rats of group one were orally administered corn oil alone at $2 \mathrm{ml} / \mathrm{kg}$. Group two rats were orally administered quercetin alone at $40 \mathrm{mg} / \mathrm{kg}$ whereas group three rats were orally administered DCM alone at $150 \mathrm{mg} / \mathrm{kg}$. Groups four, five and six rats were orally co-administered DCM $(150 \mathrm{mg} / \mathrm{kg})$ and quercetin at 10, 20 and $40 \mathrm{mg} / \mathrm{kg}$, respectively. Quercetin and DCM were separately dissolved in corn oil. Administration of DCM was done $30 \mathrm{~min}$ before quercetin treatment in the groups that received both compounds. The time interval between the treatments was to circumvent direct interaction between the compounds. The doses of DCM $(150 \mathrm{mg} / \mathrm{kg})$ and quercetin $(10,20$ and $40 \mathrm{mg} / \mathrm{kg})$ used in the present study were chosen from pilot study and previously published data (Adedara et al., 2017). Twenty-four hours following the final treatment, the animals were weighed and the samples of blood were taken from retro-orbital venous plexus into plain tubes. Thereafter, the rats were sacrificed using the cervical dislocation technique. Serum samples were subsequently prepared by centrifuging the clotted blood at $3000 \times g$ for 10 minutes. The serum samples were kept frozen at $-20^{\circ} \mathrm{C}$ until assessment of liver and kidney function biomarkers. Moreover, liver and kidney samples were immediately excised, weighed and processed for biochemical and histological analyses.

Analysis of liver and kidney function indices. Serum activities of alanine aminotransferase (ALT), aspartate aminotransferase (AST), alkaline phosphatase (ALP) and gamma glutamyl transferase (GGT) were analyzed to assess the liver functional status whereas serum urea and creatinine levels were analyzed to assess to kidney functional status using available commercial kits.

Assessment of hepatic and renal antioxidant status. Liver and kidney samples were homogenized in four volumes of $50 \mathrm{mM}$ Tris/ $\mathrm{HCl}$ buffer ( $\mathrm{pH}$ 7.4). The homogenates were subsequently centrifuged at $12000 \times g$ for $15 \mathrm{~min}$ at $4^{\circ} \mathrm{C}$ and the supernatants were used for biochemical evaluations. Hepatic and renal protein concentration was assayed using bovine serum albumin as standard according to established method (Bradford 1976).

Assay of superoxide dismutase activity. Superoxide dismutase (SOD) activity was assayed by evaluating the inhibition of autooxidation of epinephrine according to Misra and Fridovich (Misra \& Fridovich, 1972). Succinctly, the reaction mixture consisted of $20 \mu \mathrm{L}$ of the tissue sample, $2.5 \mathrm{~mL}$ of $0.05 \mathrm{M}$ carbonate buffer ( $\mathrm{pH} 10.2$ ) and $300 \mu \mathrm{L}$ of $0.3 \mathrm{mM}$ epinephrine. The increase in absorbance at $480 \mathrm{~nm}$ was monitored for $150 \mathrm{~s}$ at interval of $30 \mathrm{~s}$ using a UV-visible spectrophotometer (Shimadzu, Japan).

Assay of catalase activity. Catalase (CAT) activity was assayed by monitoring the rate of disappearance of $\mathrm{H}_{2} \mathrm{O}_{2}$ according to Aebi (Aebi, 1984). Succinctly, the reaction medium contained $1.8 \mathrm{~mL}$ of $50 \mathrm{mM}$ phosphate buffer ( $\mathrm{pH} 7.0$ ), $180 \mu \mathrm{L}$ of $300 \mathrm{mM} \mathrm{H}_{2} \mathrm{O}_{2}$, and $20 \mu \mathrm{L}$ of the tissue sample. The reaction was analyzed at $240 \mathrm{~nm}$ for $2 \mathrm{~min}$ at intervals of $10 \mathrm{~s}$ using a UV-visible spectrophotometer (Shimadzu, Japan).

Assay of glutathione level. Glutathione (GSH) level was assayed according to Ellman (Ellman, 1959). Tersely, an aliquot of tissue homogenate was mixed (1:1) with $10 \%$ TCA to precipitate the protein. The resulting supernatant was then centrifuged at $5000 \times g$ for $5 \mathrm{~min}$ and the free thiol groups were assessed in the supernatant. The reaction mixture containing $50 \mu \mathrm{L}$ of the tissue sample, $450 \mu \mathrm{L}$ phosphate buffer and $1.5 \mathrm{~mL}$ of $0.1 \mathrm{mM}$ DTNB was incubated for $10 \mathrm{~min}$ at room temperature. The absorbance of $200 \mu \mathrm{L}$ of the mixture was then measured at $412 \mathrm{~nm}$ using a SpectraMax plate reader (Molecular Devices, CA, USA).

Assay of glutathione peroxidase activity. Glutathione peroxidase (GPx) activity was assayed according to Rotruck and coworkers (Rotruck et al., 1973). Tersely, the assay mixture comprising of $50 \mu \mathrm{L}$ phosphate buffer, $20 \mu \mathrm{L}$ of $4.0 \mathrm{mM} \mathrm{GSH}, 10 \mu \mathrm{L}$ of $2.5 \mathrm{mM} \mathrm{H}_{2} \mathrm{O}_{2}, 10 \mu \mathrm{L}$ of $10.0 \mathrm{mM}$ sodium azide and $5 \mu \mathrm{L}$ of the tissue sample was prepared and the total volume was made up to 200 $\mu \mathrm{L}$ with distilled water. Subsequently, the assay mixture was incubated at $37^{\circ} \mathrm{C}$ for $3 \mathrm{~min}$, the reaction was terminated by adding $50 \mu \mathrm{L}$ of TCA $(10 \%)$ followed by centrifugation at $5000 \times g$ for $5 \mathrm{~min}$. The residual GSH level was then assayed spectrophotometrically at $412 \mathrm{~nm}$ using $50 \mu \mathrm{L}$ of the supernatant, $200 \mu \mathrm{L}$ of disodium hydrogen phosphate $(0.3 \mathrm{M})$ solution and $50 \mu \mathrm{L}$ of $0.1 \mathrm{mM}$ DTNB.

Assay of glutathione-S-transferase activity. Glutathione-S-transferase (GST) activity was assayed using 1-chloro-2,4-dinitrobenzene (CDNB) as a substrate according to Habig and others (Habig et al., 1974). Succinctly, the reaction mixture consisted of $270 \mu \mathrm{L}$ of a cocktail (20 mL of $0.25 \mathrm{M}$ phosphate buffer, $\mathrm{pH} 7.0$, $500 \mu \mathrm{L}$ of $0.1 \mathrm{M} \mathrm{GSH}$ and $10.5 \mathrm{~mL}$ of distilled water), $20 \mu \mathrm{L}$ of tissue sample and $10 \mu \mathrm{L}$ of $25 \mathrm{mM}$ CDNB. The reaction was monitored at $340 \mathrm{~nm}$ for $5 \mathrm{~min}$ at intervals of $30 \mathrm{~s}$ using a SpectraMax plate reader (Molecular Devices, CA, USA). 
Assay of lipid peroxidation. Lipid peroxidation was assessed by measuring malondialdehyde (MDA) during an acid-heating reaction according to standard procedure (Farombi et al., 2000). Briefly, reaction mixture consisted of $800 \mu \mathrm{L}$ of phosphate buffer, $200 \mu \mathrm{L}$ of tissue sample, $500 \mu \mathrm{L}$ of $10 \%$ TCA and $500 \mu \mathrm{L}$ of $0.75 \%$ TBA in $0.1 \mathrm{M} \mathrm{HCl}$. The mixture was subsequently heated at $90^{\circ} \mathrm{C}$ for $20 \mathrm{~min}$, cooled to room temperature and centrifuged at $5000 \times \mathrm{g}$ for $10 \mathrm{~min}$. The absorbance of the resulting supernatant was read at $532 \mathrm{~nm}$ and the MDA level was calculated using the extinction coefficient $(\Sigma)$ of $1.56 \times 10^{5} \mathrm{~L} / \mathrm{mol} / \mathrm{cm}$.

Histological examination. Representative samples of the liver and kidney were processed through routine stages of fixation, dehydration, clearing, infiltration and embedding before sectioning to $5 \mu \mathrm{m}$ thickness using a Rotary Microtome (Leica RM2125 RTS, Germany). The slides were stained with haematoxylin and eosin according to standard protocol (Bancroft \& Gamble, 2008). All the slides were coded before examination under a light microscope (Leica DM 500, Germany) by pathologists.

Statistical analyses. Data were presented as mean \pm standard deviation. Statistical analyses were executed using one-way analysis of variance test followed by Bonferroni's post-test using GRAPHPAD PRISM 5 software Version 4; GraphPad Software, La Jolla, California, USA). Statistical significance was set at $p<0.05$.

\section{RESULTS}

\section{Effect of quercetin on biomarkers of hepatic and renal damage in DCM-treated rats}

There were no treatment-related effect on the body weight gain and the relative weight of the liver and kidney in all the treatment groups. Renal toxicity was veri- fied by assessing the serum levels of urea and creatinine whereas hepatotoxicity was verified by assessing the serum activities of AST, ALT, GGT and ALP. In comparison with the control rats, DCM-treatment resulted in a significant $(p<0.05)$ increase in all the indices of hepatic and renal damage in the serum (Fig. 2). However, administration of quercetin to the DCM-treated rats caused a marked reduction to near normal in the serum activities of these biomarkers. Specifically, DCM administration increased the serum activities of AST, ALT, GGT and ALP by $193 \%, 167 \%, 185 \%$ and $212 \%$, respectively, when compared with the control rats. On the other hand, co-administration of $\mathrm{Qt}_{10}, \mathrm{Qt}_{20}$ and $\mathrm{Qt}_{40}$ to the DCM-treated rats caused a dose-dependent restoration in ALT activity by $51 \%, 69 \%$ and $75 \%$ and AST activity by $36 \%, 60 \%$ and $73 \%$ respectively, in the treated animals. Similarly, GGT activity was restored by $41 \%, 60 \%$ and $74 \%$ whereas ALP activity was restored by $46 \%$, $58 \%$ and $79 \%$, respectively, following co-administration of $\mathrm{Qt}_{10}, \mathrm{Qt}_{20}$ and $\mathrm{Qt}_{40}$ to DCM-treated rats. Moreover, DCM administration alone increased serum urea and creatinine levels by $294 \%$ and $108 \%$, respectively, when compared with the control rats. However, post-administration of $\mathrm{Qt}_{10}, \mathrm{Qt}_{20}$ and $\mathrm{Qt}_{40}$ to the DCM-treated animals decreased the urea level by $48 \%, 64 \%$, and $85 \%$, respectively, whereas creatinine level was reduced by $50 \%, 70 \%$ and $80 \%$, respectively.

\section{Effect of quercetin on hepatic and renal antioxidant status in DCM-treated rats}

Figure 3 shows the influence of quercetin administration on antioxidant enzymes, GSH and lipid peroxidation in the kidney and liver of rats. Acute exposure to DCM alone resulted in a significant $(p<0.05)$ decrease in the SOD, CAT, GPx and GST activities and GSH level in the kidney and liver of the treated rats. Con-
$2 a$
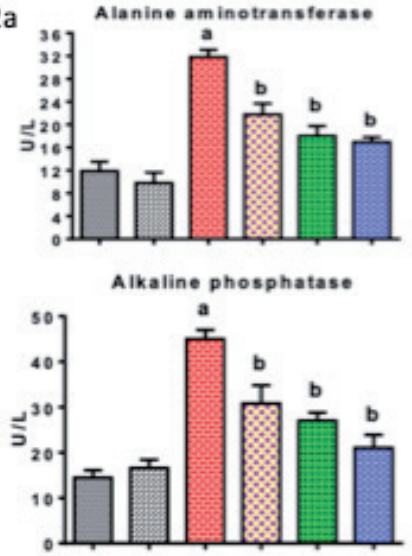

$2 \mathrm{~b}$

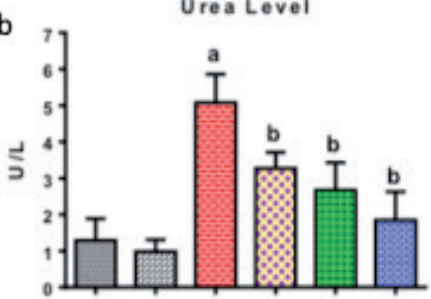

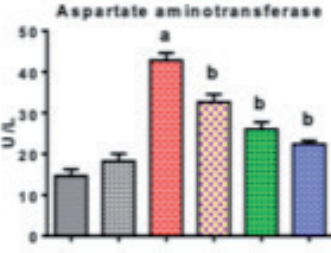
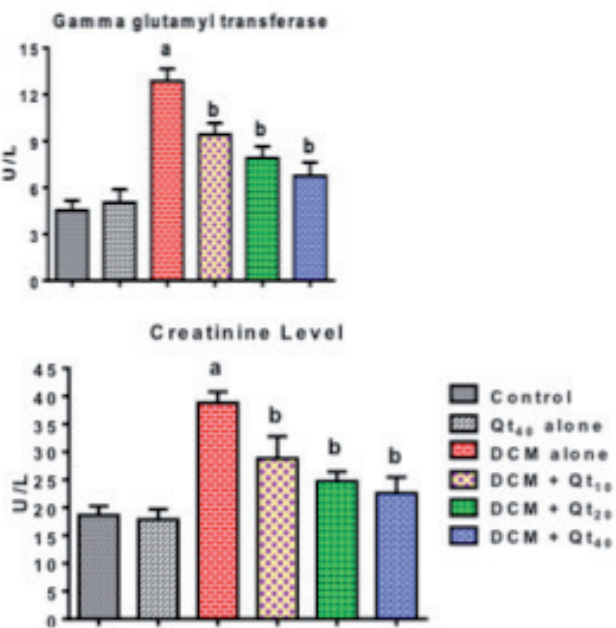

Figure 2. Effects of quercetin on biomarkers of (a) hepatic and (b) renal damage in DCM-treated rats.

$\mathrm{DCM}, 150 \mathrm{mg} / \mathrm{kg}$ dichloromethane; $\mathrm{Qt}_{1}, \mathrm{Qt}_{2}$ and $\mathrm{Qt}_{3}$ denote 10,20 and $40 \mathrm{mg} / \mathrm{kg}$ of quercetin, respectively. Each bar is mean $\pm \mathrm{S} . \mathrm{D}$. of ten rats per group aValues differ significantly from control $(p<0.05)$. ${ }^{b}$ Values differ significantly from DCM alone group $(p<0.05)$. 
3a
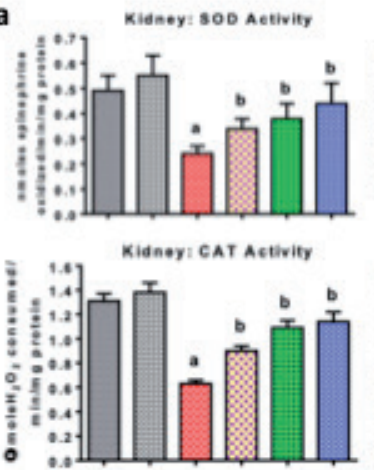

Liver: 500 Aetivity
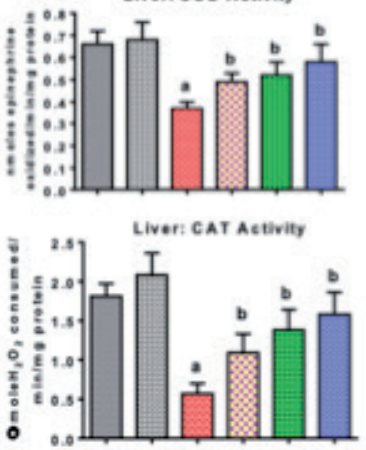

3c
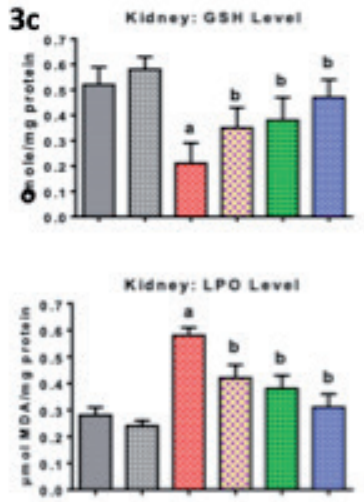

$3 \mathbf{b}$
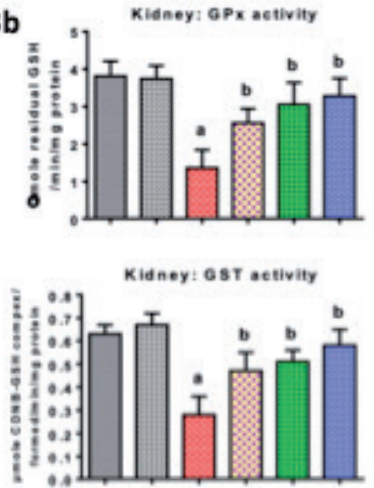

Liver: GSM Lewel
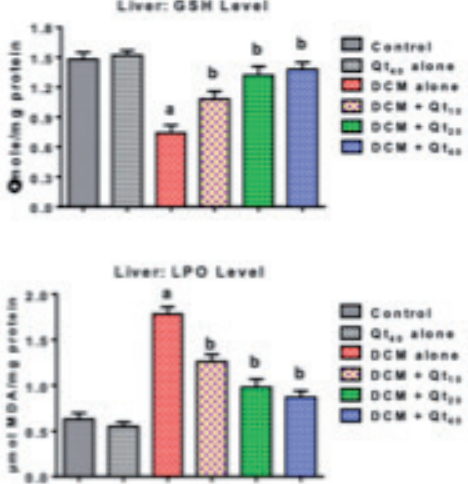

Figure 3. Effects of quercetin on (a) SOD, CAT, (b) GPx, GST, (c) GSH and LPO levels in liver and kidney of DCM-treated rats.

$\mathrm{DCM}, 150 \mathrm{mg} / \mathrm{kg}$ dichloromethane; $\mathrm{Qt}_{1}, \mathrm{Qt}_{2}$ and $\mathrm{Qt}_{3}$ denote 10, 20 and $40 \mathrm{mg} / \mathrm{kg}$ of quercetin, respectively. Each bar is mean $\pm \mathrm{S} . \mathrm{D}$. of ten

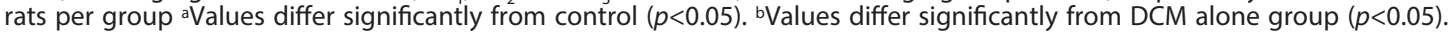

$4 a$
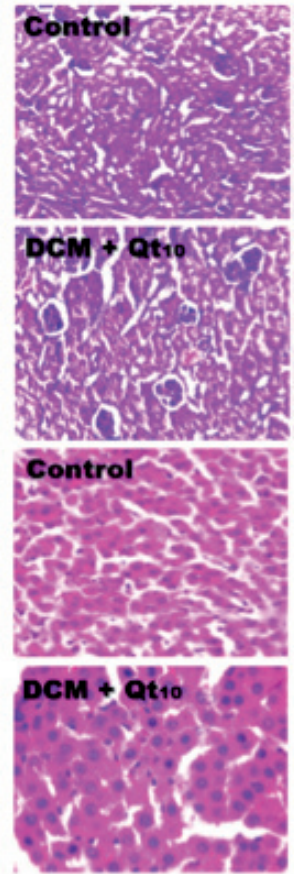
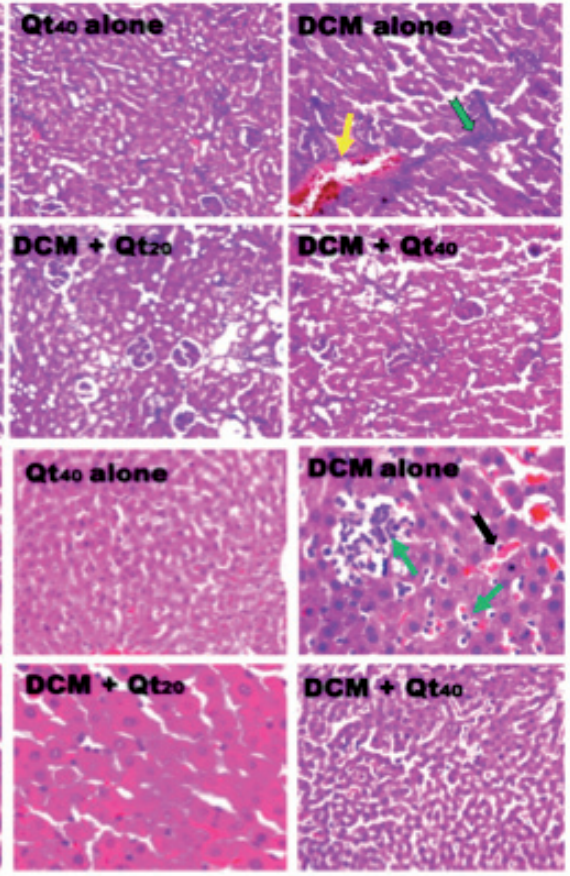

Figure 4. Representative photomicrographs of the kidney and liver from control and experimental rats.

(a) Kidney of control and quercetin alone rats showing normal morphology. Kidney of rats treated with DCM alone showing congestion of vessels (yellow arrow) and infiltration of inflammatory cells (green arrow). Kidney of rats co-exposed to DCM and quercetin at 10, 20 and $40 \mathrm{mg} / \mathrm{kg}$ appear somewhat similar to control. (b) Liver of rats treated with DCM alone showing marked disseminated congestion (black-notched arrow), focal area of lymphoid aggregate and mild infiltration of zone 2 by inflammatory by cells (green arrow). Liver of rats co-exposed to DCM and quercetin at 10, 20 and $40 \mathrm{mg} / \mathrm{kg}$ showing appear somewhat similar to control. Original magnification: 200x. 
versely, administration of quercetin mitigated against the decrease in the SOD, CAT, GPx and GST activities as well as GSH level, and re-established the hepatic and renal levels to near normal in DCM-treated rats. Furthermore, administration of DCM alone caused a significant increase in the levels of MDA, an established known index of lipid peroxidation, in the kidney and liver of the treated rats. However, administration of quercetin to DCM-treated rats markedly reduced MDA levels in the liver and kidney when compared with DCM alone group. DCM administration alone increased MDA level in the liver and kidney by $183 \%$ and $105 \%$, respectively, when compared with the control rats. Administration of $\mathrm{Qt}_{10}, \mathrm{Qt}_{20}$ and $\mathrm{Qt}_{40}$ to the DCM-treated caused renal MDA level to decrease by $53 \%, 66 \%$, and $90 \%$ whereas hepatic MDA level was reduced by $45 \%, 70 \%$ and $79 \%$, respectively.

\section{Effects of quercetin on DCM-induced histopathological lesions in liver and kidney of rats}

The representative photomicrographs of the kidney and liver of experimental rats are depicted in Fig. 4. The glomeruli and hepatocytes of control rats appeared normal with well-preserved morphology, in contrast to the kidney of rats administered DCM alone that exhibited congestion of vessels (yellow arrow) and infiltration of inflammatory cells (green arrows). The liver of rats administered DCM alone exhibited marked disseminated congestion (black notched arrow), focal area of lymphoid aggregate with mild infiltration of zone 2 by inflammatory cells (green arrow). The lesions identified in kidney and liver of DCM-treated rats was independent of the vehicle corn oil. However, the kidney and liver of rats co-administered with quercetin exhibited normal structure. The renal and hepatic cells of rats co-administered with $\mathrm{Qt}_{10}, \mathrm{Qt}_{20}$ and $\mathrm{Qt}_{40}$ appeared structurally and functionally normal.

\section{DISCUSSION}

This study demonstrates the beneficial role of quercetin on DCM-induced hepatorenal toxicity in rat and provides evidence that this effect is due to quercetin's antioxidant mechanism of action. DCM treatment resulted in elevated renal and hepatic MDA level. MDA and 4-hydroxynonenal are biomarkers of lipid peroxidation (Demir et al., 2011), attacking distant targets and covalently binding with biomolecules (Levent et al., 2006). Reduction in MDA level in rats co-treated with quercetin indicates its ability to protect against DCM mediated lipid peroxidation, due to its antioxidant activity (Xiao et al., 2018). DCM treatment also resulted in decreased hepatorenal antioxidant enzymes (SOD, CAT, GPx), essential for superoxide radical biotransformation to $\mathrm{H}_{2} \mathrm{O}_{2}$, thus preventing its damaging effects (Klaunig et al., 2011) on one hand and cytotoxicity by transforming $\mathrm{H}_{2} \mathrm{O}_{2}$ to water and oxygen (Kohen \& Nyska, 2002; Adedara et al., 2012) on the other hand. Decrease in antioxidant enzymes results in ROS production. ROS bioaccumulation aggravates oxidative stress, disrupts cellular membrane integrity and induces cytotoxic damage (Ratliff et al., 2016; Pizzino et al., 2017). DCM treated rats; antioxidant activities were enhanced by quercetin co-treatment. Thus, the restoration of hepatorenal antioxidant capacity in quercetin-treated rats is attributed to its free radical scavenging ability.

Glutathione is well known to interact directly with ROS using its thiol group or act as a co-substrate during biochemical conjugation of xenobiotics by GST to prevent cellular oxidative damage (Singh et al., 2002). Reduction in GSH level and GST activity in the target organs of DCM-treated rats suggests utilization of GSH and GST inhibition. Co-treatment with quercetin reversed this trend, further highlighting the benefit of quercetin.

Elevated hepatic transferases in serum manifest hepatocellular injury and dysfunction (Kaplan, 1993; Lin et al., 2003; Adedara et al., 2010; Owumi et al., 2019). Since they are located primarily in hepatocytes, their increased serum activities indicate hepatocyte membranes injury. Similarly, elevation in serum urea and creatinine levels indicates renal dysfunction observed in DCM-treated rats. Increased creatinine level connotes impairment in glomerular filtration rate of kidney, whereas elevation of the urea level signifies diminished re-absorption at the renal epithelium (Adedara et al., 2012). Quercetin effectively chemo-protects rats against DCM-mediated oxidative damage, decreases hepatorenal injury biomarkers, possibly via preservation of membrane integrity and enhancing endogenous antioxidant capacity.

Histopathological examination of the kidney and liver supports biochemical data on DCM-induced oxidative injury in treated rats. Kidneys of the treated animals showed vascular congestion and infiltration of inflammatory cells, whereas the liver presented marked disseminated congestion and focal area of lymphoid aggregate. Co-treatment with quercetin limited DCM-induced tissues injury.

Overall, biochemical and histological data showed that quercetin conferred dose-dependent protection against DCM-induced hepatorenal injury. Conclusively, DCM mediated induction of oxidative stress is correlated with hepatorenal impairment. Quercetin abrogated this trend by mechanisms associated with inhibition of lipid peroxidation and enhancement of antioxidant defense status. Dietary supplementation with quercetin may hold promise against hepatorenal injury due to the exposure to DCM or related chemical compounds.

\section{Conflict of interest}

The authors have no conflicts of interest to declare.

\section{Acknowledgements}

This research was done without specific grant from any funding agency in the public, commercial, or notfor-profit sectors.

\section{REFERENCES}

Adedara IA, Ego VC, Subair TI, Oyediran O, Farombi EO (2017) Quercetin improves neurobehavioral performance through restoration of brain antioxidant status and acetylcholinesterase activity in manganese-treated rats. Neurochem Res 42: 1219-1229. https://doi. org/10.1007/s11064-016-2162-z

Adedara IA, Owumi SE, Uwaifo AO, Farombi EO (2010) Aflatoxin $\mathrm{B}_{1}$ and ethanol co-exposure induces hepatic oxidative damage in mice. Toxicol Ind Health 26: 717-1724. https://doi. org/10.1177/0748233710377772

Adedara IA, Teberen R, Ebokaiwe AP, Ehwerhemuepha T, Farombi EO (2012) Induction of oxidative stress in liver and kidney of rats exposed to Nigerian bonny light crude oil. Environ Toxicol 27: 372 379. https://doi.org/10.1002/tox.20660

Aebi H (1984) Catalase in vitro. Methods Ensymol 105: 121-126. PMID: 6727660

Agency for Toxic Substances and Disease Registry (ATSDR). Toxicological Profiles, Methylene Chloride, September 2000

Babaei F, Mirzababaei M, Nassiri-Asl M (2018) Quercetin in food: possible mechanisms of its effect on memory. J Food Sci 83: 2280-2287. https://doi.org/10.1111/1750-3841.14317

Bancroft JD, Gamble M (2008) Theory and Practice of Histology Techniques, 6th edn, pp 83-134. Churchill Livingstone Elsevier. 
Boots AW, Haenen GR, Bast A (2008) Health effects of quercetin: from antioxidant to nutraceutical. Eur J Pharmacol 585: 325-337. https://doi.org/10.1016/j.ejphar.2008.03.008

Bradford MM (1976) Rapid and sensitive method for the quantitation of microgram quantities of protein utilizing the principle of proteindye binding. Anal Biochem 72: 248-254

Chen C, Zhou J, Ji C (2010) Quercetin: a potential drug to reverse multidrug resistance. Life Sci 87: 333-338. https://doi.org/10.1016/j. lfs.2010.07.004

Condie LW, Smallwood CL, Laurie RD (1983) Comparative renal and hepatotoxicity of halomethanes: bromodichloromethane, bromoform, chloroform, dibromochloromethane and methylene chloride. Drug Chem Toxicol 6: 563-578. https://doi. org/10.3109/01480548309017810

Costa LG, Tait L, de Laat R, Dao K, Giordano G, Pellacani C, Cole TB, Furlong CE (2013) Modulation of paraoxonase 2 (PON2) in mouse brain by the polyphenol quercetin: a mechanism of neuroprotection? Neurochem Res 38: 1809-1818. https://doi.org/10.1007/ s11064-013-1085-1

D'Andrea G (2015) Quercetin: A flavonol with multifaceted therapeutic applications? Fitoterapia 106: 256-271. https://doi.org/10.1016/j. fitote.2015.09.018

Demir E, Kaya B, Soriano C, Creus A, Marcos R (2011) Genotoxic analysis of four lipid-peroxidation products in the mouse lymphoma assay. Mutat Res 726: 98-103. https://doi.org/10.1016/j.mrgentox.2011.07.001

Ebegboni VJ, Dickenson JM, Sivasubramaniam SD (2019) Antioxidative effects of flavonoids and their metabolites against hypoxia/ reoxygenation-induced oxidative stress in a human first trimester trophoblast cell line. Food Chem 272: 117-125. https://doi. org/10.1016/j.foodchem.2018.08.036

Ellman GL (1959) Tissue sulfhydryl groups. Arch Biochem Biophys 82: 70-77. PMID: 13650640

Evans MV, Caldwell JC (2010) Evaluation of two different metabolic hypotheses for dichloromethane toxicity using physiologically based pharmacokinetic modeling for in vivo inhalation gas uptake data exposure in female B6C3F1 mice. Toxicol Appl Pharmacol 244: 280290. https://doi.org/10.1016/j.taap.2010.01.018

Farombi EO, Tahnteng JG, Agboola AO, Nwankwo JO, Emerole GO (2000) Chemoprevention of 2-acetylaminofluorene-induced hepatotoxicity and lipid peroxidation in rats by kolaviron-a Garcinia kola seed extract. Food Chem Toxicol 38: 535-541. PMID: 10828505

Habig WH, Pabst MJ, Jakoby WB (1974) Glutathione S-transferase. The first enzymatic step in mercapturic acid formation. $J$ Biol Chem 249: 7130-7139. PMID: 4436300

Harwood M, Danielewska-Nikiel B, Borzelleca JF, Flamm GW, Williams GM, Lines TC (2007) A critical review of the data related to the safety of quercetin and lack of evidence of in vivo toxicity, including lack of genotoxic/carcinogenic properties. Food Chem Toxicol 45: 2179-2205. https://doi.org/10.1016/j.fct.2007.05.015

Hermon L, Denonfoux J, Hellal J, Joulian C, Ferreira S, Vuilleumier S, Imfeld G (2018) Dichloromethane biodegradation in multi-contaminated groundwater: Insights from biomolecular and compoundspecific isotope analyses. Water Res 142: 217-226. https://doi. org/10.1016/j.watres.2018.05.057

Houghton MJ, Kerimi A, Tumova S, Boyle JP, Williamson G (2018) Quercetin preserves redox status and stimulates mitochondrial function in metabolically-stressed HepG2 cells. Free Radic Biol Med 129: 296-309. https://doi.org/10.1016/j.freeradbiomed.2018.09.037

HPD (2009) Household Products Database. National Library of Medicine. http://hpd.nlm.nih.gov/ingredients.htm and search on CAS number

Jianming Y, Wei L, Zhuowei C, Yifeng J, Wenji C, Jianmeng C (2014) Dichloromethane removal and microbial variations in a combination of UV pretreatment and biotrickling filtration. J Hazard 268: 14-22. https:/ / doi.org/10.1016/j.jhazmat.2013.12.068

Kaplan MM (1993) Laboratory tests In Schiff L, Schiff ER eds, Diseases of the Liver, 7th edn, pp 108-144. JB Lippinocott, Philadephia
Klaunig JE, Wang Z, Pu X, Zhou S (2011) Oxidative stress andoxidative damage in chemical carcinogenesis. Toxicol Appl Pharmacol 254: 86-99. https://doi.org/10.1016/j.taap.2009.11.028

Kohen R, Nyska A (2002) Oxidation of biological systems: oxidative stress phenomena, antioxidants, redox reactions, and methods for their quantification. Toxicol Pathol 30: 620-650. https://doi. org/10.1080/01926230290166724

Levent G, Ali A, Ahmet A, Polat EC, Aytac C, Ayse E, Ahmet S (2006) Oxidative stress and antioxidant defense in patients with chronic hepatitis $\mathrm{C}$ patients before and after pegylated interferon alfa-2b plus ribavirin therapy. J Transl Med 4: 25. https://doi. org/10.1186/1479-5876-4-45

Lin TJ, Su CC, Lan CK, Jiang DD, Tsai JL, Tsai MS (2003) Acute poisonings with Breynia officinalis - an outbreak of hepatotoxicity. $J$ Toxicol Clin Toxicol 41: 591-594. PMID: 14514003

Misra HP, Fridovich I (1972) The role of superoxide anion in the autooxidation of epinephrine and a simple assay for superoxide dismutase. I Biol Chem 247: 3170-3175. PMID: 4623845

Nair HB, Sung B, Yadav VR, Kannappan R, Chaturvedi MM, Aggarwal BB (2010) Delivery of anti-inflammatory nutraceuticals by nanoparticles for the prevention and treatment of cancer. Biochem Pharmacol 80: 1833-1843. https://doi.org/10.1016/j.bcp.2010.07.021

Owumi SE, Dim UJ (2019) Manganese suppresses oxidative stress, inflammation and caspase-3 activation in rats exposed to chlorpyrifos. Toxicology Reports 6: 202-209. https://doi.org/10.1016/j. toxrep.2019.02.007.

Pandey MK, Gupta SC, Karelia D, Gilhooley PJ, Shakibaei M, Aggarwal BB (2018) Dietary nutraceuticals as backbone for bone health. Biotechnol Adv 36: 1633-1648. https://doi.org/10.1016/j.biotechadv.2018.03.014

Pizzino G, Irrera N, Cucinotta M, Pallio G, Mannino F, Arcoraci V, Squadrito F, Altavilla D, Bitto A (2017) Oxidative stress: harms and benefits for human health. Oxid Med Cell Longev 2017: 8416763. https://doi.org/10.1155/2017/8416763

Ratliff BB, Abdulmahdi W, Pawar R, Wolin MS (2016) Oxidant mechanisms in renal injury and disease. Antioxid Redox Signal 25: 119146. https://doi.org/10.1089/ars.2016.6665

Rauf A, Imran M, Khan IA, Ur-Rehman M, Gilani SA, Mehmood Z, Mubarak MS (2018) Anticancer potential of quercetin: A comprehensive review. Phytother Res https://doi.org/10.1002/ptr.6155

Rotruck JT, Pope AL, Ganther HE, Swanson AB, Hafeman DG, Hoekstra WG (1973) Selenium: biochemical role as a component of glutathione peroxidase. Science 179: 588-590. PMID: 4686466

Schlosser PM, Bale AS, Gibbons CF, Wilkins A, Cooper GS (2015). Human health effects of dichloromethane: key findings and scientific issues. Environ Health Perspect 123: 114-119. https://doi. org/10.1289/ehp.1308030.

Sharma A, Kashyap D, Sak K, Tuli HS, Sharma AK (2018) Therapeutic charm of quercetin and its derivatives: a review of research and patents. Pharm Pat Anal 7: 15-32. https://doi.org/10.4155/ppa2017-0030

Shestakova M, Sillanpää M (2013) Removal of dichloromethane from ground and wastewater: a review. Chemosphere 93: 1258-1267. https://doi.org/10.1016/j.chemosphere.2013.07.022

Singh SP, Janecki AJ, Srivastava SK, Awasthi S, Awasthi YC, Xia SJ, Zimniak P (2002) Membrane association of glutathione S-transferase mGSTA4-4, an enzyme that metabolizes lipid peroxidation products. J Biol Chem 277: 4232-4239. https://doi.org/10.1074/jbc. M109678200

Tobajas M, Verdugo V, Polo AM, Rodriguez JJ, Mohedano AF (2016) Assessment of toxicity and biodegradability on activated sludge of priority and emerging pollutants. Environ Technol 37: 713-721

Xiao L, Luo G, Tang Y, Yao P (2018) Quercetin and iron metabolism: What we know and what we need to know. Food Chem Toxicol 114: 190-203. https://doi.org/10.1080/09593330.2015.1079264

Zizkova P, Stefek M, Rackova L, Prnova M, Horakova L (2017) Novel quercetin derivatives: From redox properties to promising treatment of oxidative stress related diseases. Chem Biol Interact 265: 36-46. https://doi.org/10.1016/j.cbi.2017.01.019 